\title{
Configurações
}

Revista de sociologia

\section{"Agora sou velho demais para trabalhar": uma leitura sociológica de memórias e vivências do trabalho e de desemprego em fim de carreira profissional}

"Now I am too old to work": a sociological reading of memories and experiences of work and unemployment at career's end «Maintenant je suis trop vieux pour travailler»: une lecture sociologique de la mémoire et des expériences de travail et de chômage en fin de carrière professionnelle

\section{Manuel Carlos Silva e Rita Borges Neves}

\section{CpenEdition}

\section{Edição electrónica}

URL: http://journals.openedition.org/configuracoes/3296

DOI: $10.4000 /$ configuracoes.3296

ISSN: $2182-7419$

Editora

Centro de Investigação em Ciências Sociais

\section{Edição impressa}

Data de publição: 27 Junho 2016

Paginação: $213-230$

ISSN: 1646-5075

\section{Refêrencia eletrónica}

Manuel Carlos Silva e Rita Borges Neves, " "Agora sou velho demais para trabalhar": uma leitura sociológica de memórias e vivências do trabalho e de desemprego em fim de carreira profissional », Configurações [Online], 17 | 2016, posto online no dia 30 junho 2016, consultado o 01 maio 2019. URL : http://journals.openedition.org/configuracoes/3296; DOI : 10.4000/configuracoes.3296 
Silva, Manuel Carlos; Neves, Rita Borges - "Agora sou velho demais para trabalhar": uma leitura sociológica de memórias e vivências do trabalho e de desemprego em fim de carreira profissional. Configurações, vol. 17, 2016, pp. 213-230

\title{
"Agora sou velho demais para trabalhar": uma leitura sociológica de memórias e vivências do trabalho e de desemprego em fim de carreira profissional
}

\author{
MANUEL CARLOS SILVA* \\ Universidade do Minho \\ RITA BORGES NEVES** \\ Universidade do Minho
}

\section{Resumo}

Vítor e Rui, que trabalham desde tenra idade e exercem funções manuais e pouco especializadas a troco de magros salários, enfrentam a extinção do seu posto de trabalho aos 60 anos na sequência do encerramento das respectivas fábricas. Porém, enquanto Vítor se sente aliviado dos constrangimentos e da sobrecarga física e psicológica, já Rui não se sente bem como desempregado por, em contraste com as memórias de um sentimento de pertença no passado, deixar de participar na rotina diária de um projecto comum, o que lhe causa mal-estar. Tal implica abdicar de um papel socialmente valorizado nas sociedades ocidentais, tradicionalmente associado à idade adulta e à masculinidade, e enquadrar-se precocemente num novo rótulo e numa fase de vida conotada negativamente, "a terceira idade".

O presente texto pretende reflectir sobre as memórias de trabalho e vivências do desemprego em trabalhadores "mais velhos", e de como as estratégias para lidar com a hetero-exclusão do mercado de trabalho podem passar pela incorporação de uma identidade deteriorada, associada a inactividade e inutilidade. Nesse sentido, as histórias de vida de Vítor e de Rui, bem como os seus discursos relativamente ao emprego e ao desemprego, ao reavivarem memórias e sentimentos de utilidade enquanto trabalhadores, ilustram uma leitura sociológica do fenómeno do desemprego como mecanismo de exclusão dentro de uma lógica neoliberal de selecção e de valorização dos indivíduos

\footnotetext{
* Investigador integrado no Centro Interdisciplinar de Ciências Sociais, polo Universidade do Minho. Email: mcsilva2008@gmail.com.

** Doutoranda no Centro Interdisciplinar de Ciências Sociais, polo Universidade do Minho, com Bolsa de Doutoramento financiada pela Fundação para a Ciência e a Tecnologia (Ref. SFRH/BD/6731/2009). Email: ritaborgesneves@gmail.com.
} 
em função do seu valor na cadeia produtiva e/ou a sua dispensa em caso de reestruturação ou deslocalização de empresas.

Palavras-chave: memórias, trabalho, desemprego, identidade, terceira idade.

\section{Abstract \\ "Now I am too old to work": a sociological reading of memories and experiences of work and unemployment at career's end}

Vítor and Rui who work from an early age and have conducted unskilled manual work while facing strenuous tasks in exchange for a low wage. Although Vítor feels relieved of the constraints and of physical and psychological overload. In contrast, Rui does not feel well because unemployment, in contrast with his memories and past sense of belonging, means he no longer participates in the daily routine of a common project. This causes unease and implies giving up a socially valued role in western societies--a role traditionally associated with adulthood and masculinity. It requires him, before he is ready, to assume a new label and to fit himself into a new stage of life socially defined as negative: "the third age".

This paper reflects upon the memories of work and the experience of unemployment among older workers while aiming to shed some light upon the strategies that these unemployed find to deal with the hetero-exclusion from which they suffer. This means incorporating a degraded identity, associated with inactivity and uselessness, representative of "social aging". In this sense, the life histories of Vítor and Rui, as well as their self-discourse about employment and unemployment, bring about memories and feelings of their uselessness as workers and as productive individuals. Such lives illustrate a sociological reading of the phenomenon of unemployment as a mechanism of exclusion within a neoliberal logic of selection, under which the value of the individual is defined by one's output in the chain of production and/or by one's redundancy in cases of restructure/relocation.

Keywords: memories, work, unemployment, identity, old age.

\section{Résumé \\ "Maintenant je suis trop vieux pour travailler» : une lecture sociologique de la mémoire et des expériences de travail et de chômage en fin de carrière professionnelle}

Vítor et Rui qui travaillent dès leur plus jeune âge et exercent des fonctions manuelles et peu spécialisées pour de maigres salaires, font face à l'extinction de leur poste de travail à 60 ans, à la suite de la fermeture de leur usine. Cependant, tandis que Vítor se sent soulagé de ses contraintes et de la surcharge physique et psychologique, Rui ne se sent pas bien au chômage parce que, contrairement à la mémoire du sentiment d'appartenance ressenti dans le passé, il ne participe plus à la routine quotidienne d'un projet commun, ce qui provoque chez lui un malaise. Car c'est abdiquer d'un rôle socialement valorisé dans les sociétés occidentales, traditionnellement associé à l'âge adulte et à la masculinité et s'adapter précocement à une nouvelle étiquette et à une phase de la 
vie connotée négativement : le "troisième âge ". Cet article prétend réfléchir sur les souvenirs de travail et sur l'expérience du chômage chez les ouvriers "plus âgés » ainsi que sur la façon dont les stratégies en jeu dans l'hétéro-exclusion du marché du travail peuvent passer par l'incorporation d'une identité détériorée, associée à l'inactivité et à l'inutilité représentatives d'un processus de «vieillissement social ». Dans ce sens, les histoires de vie de Vítor et Rui, tout comme leurs discours sur l'emploi et le chômage, en ravivant des mémoires et des sentiments d'utilité en tant qu'ouvriers, illustrent une lecture sociologique du phénomène du chômage comme un mécanisme d'exclusion dans une logique néolibérale de sélection et de valorisation des individus en fonction de leur valeur dans la chaine de production et/ou de leur licenciement en cas de restructuration ou délocalisation d'entreprises.

Mots-clés: mémoires, travail, chômage, identité, vieillesse.

\section{Introdução: o problema}

O trabalho é um conceito nuclear, ainda que contestado e questionado a partir de diversas conceções. Independentemente da diversidade de sentidos, trata-se de um conceito e de uma realidade incontornável em termos de identidade social, à qual se associam, em termos individuais e coletivos, diversos e até opostos significados pela reconstituição ora positiva, ora negativa das memórias em função das experiências do trabalho no passado em confronto com o desemprego no presente.

Em Portugal são já conhecidos trabalhos de ordem teórica e empírica sobre classes e situações de classe ${ }^{1}$, sendo de referir uns mais orientados sobre classes sociais nos campos, outros sobre classes sociais no sector secundário nomeadamente na construção e indústria, sendo de destacar o trabalho de Estanque (1999) em contexto fabril, entre os operários do calçado em São João da Madeira, em que as memórias dos indivíduos são evocadas por referência às memórias coletivas de grupo ou presentes na sociedade.

O trabalho de recolha empírica assume a abordagem metodológica weberiana centrada no individualismo metodológico, ou seja, partindo do particular para o geral, das recordações, motivações e dos significados atribuídos pelos atores sociais a fim de compreender e explicar, com base numa ou mais causas, os impactos do fenómeno do desemprego e, por contraponto, em contexto passado, as vivências reconstituídas do trabalho no passado. Para tal foram selecionados dois estudos de caso, cujos protagonistas são desempregados acima dos 55 anos: o Rui com 55 anos que vive e sofre a situação de desempregado como uma desclassificação, cujo significado e relativa perda

1 Sobre classes sociais, importa ter presente os estudos de Almeida (1986) e Pinto (1985), Silva (1998, 2007 e 2009), Costa (1987), Estanque e Mendes (1997), Estanque (1999), Costa, Mauriti e Martins (2004), Pereira (2006), Queiroz (2007). Sobre recomposição social, cf. Almeida, Costa e Machado (1994). 
de autoestima convoca as memórias em torno do trabalho no passado; e o Vítor com 61 anos que, perante uma vida de trabalho duro e penoso, assume a entrada no desemprego e na reforma como um alívio, ou seja, a memória penosa do trabalho no passado converte o desemprego e a reforma antecipada como gratificações no presente.

Com base em fragmentos de histórias de vida e certos relatos e narrativas extraídas dos dois entrevistados se reconstituem memórias e vivências do passado laboral e emergem traços comuns e distintivos de grupos de desempregados, podendo ser assumidos como tipos-ideais a partir dos quais é possível retratar vidas duras e penosas de trabalhadores assalariados.

\section{Memória: interações entre o passado e o presente}

O conceito de memória, já esboçado nos pactos dos escritos bíblicos entre a divindade e o povo e na antiguidade greco-latina, é retomado no renascimento, quer, primeiro, pelas mnemotécnicas orais e retóricas, quer, posteriormente, pela escrita e pelo ideal enciclopédico, instrumentos de recuperação e legitimação da realidade e da vida em contraponto com o esquecimento e a morte - esta última, eventualmente precedida de amnésias e, em regimes totalitários, nomeadamente fascistas, de destruição, manipulação ou cancelamento seletivo de memórias (cf. Montesperelli, 2000: 17 ss; Todorov, 2000). No entanto, este conceito virá a ser sociologicamente trabalhado por diversos autores com particular destaque para a corrente estruturo-funcional, segundo a qual existe uma certa homologia e tensão entre a 'densidade material' e a 'densidade moral' ou até complementaridade entre a morfologia físico-espacial e a morfologia social (cf. respetivamente Durkheim, 1991 e Halbwachs, 1968)². Com efeito, para Durkheim (1991), o espaço constitui a primeira experiência da vida e as representações do espaço estão estreitamente ligadas ao quadro não só físico como social do modo de existência, do trabalho e do habitat dos atores sociais. Ou seja, em termos mais estritos, memória individual pressupõe uma memória coletiva referente ao passado, como o advertem os autores citados, e, como tal, remete para um determinado tipo de organização social, aos factos sociais como "modos de pensar e agir", aos espaços e correlativos lugares laborais e residenciais, às criações artísticas, ao vaivém da mobilidade geográfica e social, aos edifícios e aos usos de espaços da rotina quotidiana, às sociabilidades $\mathrm{e}$

\footnotetext{
2 Esta homologia e correspondência entre a coisa (res) e os termos (termini), entre os princípia essendi et cognoscendi, em suma, entre a ontologia e a gnosiologia e/ou a lógica, estaria já bem presente na velha e essencialista metafísica aristotélica-tomista apostada em desvendar a essência das coisas, a qual viria todavia a ser posta em causa pelo método de clareza e rigor instaurados por Bacon e Descartes (cf. Rossi in Montesperelli, 2000: 36; Mora, 2009). Esta temática viria a ser mais tarde desenvolvida num registo materialista e desconstrução de traços essencialistas e idealistas por parte de Marx e Engels (1976). Sobre a memória e sobre o modo como as sociedades recordam, cf. Halbawachs, 1968, 1994; Connerton, 1989.
} 
demais práticas socio-espaciais. Neste quadro, e na esteira do pensamento durkheimiano em torno da relativa subalternização da consciência individual perante a consciência coletiva (cf. Durkheim, 1977), foi particularmente Halbwachs $(1968,1994)$ quem, de modo mais sistematizado, teorizou sobre a memória e fez sustentar as memórias dos indivíduos na memória coletiva (linguagens, imagens, representações espácio-temporais, narrativas e testemunhos orais, textos e arquivos, denominações e classificações de objetos, realidades externas), como substrato de coesão e identidade social derivada de determinado ambiente societal.

Porém, esta temática irá também suscitar, ainda que numa perspetiva diferente, a atenção da fenomenologia (Schutz e Luckman, 1977) e do interacionismo simbólico na medida em que é sublinhada a importância da interação social na fixação e na reprodução das recordações em torno das representações e comemorações do passado, como o sublinha Nora (1978: 59): “o que fica do passado na vivência dos grupos, ou o que estes grupos fazem com o passado". Está aqui subjacente a ideia, aliás fecundamente desenvolvida por Sobral (1999), respetivamente aos diversos tipos de casas e famílias (proprietários, pequenos camponeses), o que se reflete em diferentes tipos de mementos: desde a casa, recheio (v.g., quadros, louças, pratas), objetos e artefactos diversos, recordações, narrativas, recursos e mementos que as famílias mais pobres (v.g., jornaleiros) não possuem, salvo as memórias dos seus escassos recursos e percursos de trabalho, exploração e sofrimento. Ou seja, os grupos e, consequentemente, as famílias e os indivíduos interpretam e selecionam, revivem e reatualizam determinadas representações a partir do seu lugar social, de uma certa mundividência ou como resultado de compromissos, dando assim o mesmo facto social (v.g., a experiência laboral ou residencial) origem a diversas interpretações e representações conforme os grupos ou categorias sociais em competição não só na esfera privada como sobretudo na esfera pública em busca da legitimação e da interpretação hegemónica. Esta ideia vai de resto ao encontro da abordagem marxista quando reivindica que a ideologia, enquanto substrato depositário de um conjunto de ideias, signos e símbolos, incluindo obviamente o arsenal de memórias, traduz as ideias das classes dominantes (cf. Marx e Engels, 1976).

Esta última perspetiva da pluralidade de memórias coletivas por classes ou grupos sociais não só dominantes mas também subalternos e 'vencidos', defendida aliás pela 'nova história' (cf. Le Goff, 1978), é mais consentânea não só com a ideia de celebração do passado como também com a experiência vivida (vorwelt) e socializadora numa perspetiva acionalista, fenomenológica e interacionista (cf. respetivamente Weber 1922; Schutz e Luckman 1977). Porém, o mais relevante é que esta perspetiva é também reassumida posteriormente por Halbwachs (1968), quando refere numa alusão de teor marxizante que "as ideias do poder dominante são a memória dominante” ou, ainda a propósito 
da relação entre memória individual e memória coletiva: "Cada memória individual é um ponto de vista sobre a memória coletiva: este ponto de vista muda conforme o lugar que se ocupa no seu interior e, por sua vez, este lugar muda consoante as relações que cada um mantenha com os demais círculos sociais. Não deve pois surpreender que do instrumento comum cada um não extraia o mesmo ponto de vista" (Halbwachs, 1994: 61). Onde, porém, a perspetiva estruturalista, ainda que moderada, de Halbwachs (1994) não cede é na ideia de que, não obstante a pluralidade e diversidade de segmentos de memória, todas elas constituem produtos sociais exteriores aos indivíduos. Por fim, a respeito da memória e seu contraponto, o esquecimento, importa ter presente os contributos de Joel Candau (2012) e, sobretudo, de Marc Augé (1998). Com efeito, estes autores sublinham a importância do esquecimento como a contraparte facial da memória, argumentando que aquele é tão importante como a memória não só para a vida social como para a vida individual de cada pessoa humana. Como argumenta Fernando Bessa Ribeiro (2010), na esteira dos autores referidos, sem esquecimento os indivíduos viveriam toldados pela recordação constante das 'más memórias', ficando assim impedidos de encontrar formas de compromisso e convívio necessárias à vida em comum.

\section{Trabalho e desemprego: conceções em confronto}

Trabalho é um conceito e uma característica nuclear em todas as sociedades. Se o significado etimológico de trabalho (tripaliare $=$ trabalhar $=$ torturar) remetia para uma conceção expiatória, foram diversos os significados que o trabalho teve ao longo da história e nos diferentes tipos de sociedades ${ }^{3}$. No entanto, o seu significado dominante emerge na idade moderna e é conceptualizado nas sociedades contemporâneas, emergindo a perspetiva liberal como um das primeiras correntes que aborda o trabalho como um conjunto de atividades que tem em vista não só garantir a segurança material como a produção de bens e serviços, processo este que na economia de mercado tem lugar através da lei da oferta e da procura, estabelecendo-se assim o designado mercado de trabalho.

Sem menosprezar os contributos dos liberais e dos socialistas utópicos, foi de facto Marx (1974) quem, de modo inovador, veio conceber o trabalho como uma atividade produtora de valores de uso e, no quadro do modo de produção capitalista, também de valores de troca, de mercadorias. O trabalho compreende não só a transformação da natureza como comporta aspetos relacionais entre classes sociais. $\mathrm{O}$ trabalho tem duas componentes: uma que é o trabalho socialmente necessário pelo qual o trabalhador recebe um salário em vista da sua reprodução social e satisfação das suas necessidades e outra 
traduzida na produção de mais-valia. Esta última componente, embora hoje possa ser acumulada pelo capital global, no século XIX era apropriada pelas diferentes frações do capital: a renda para o proprietário, o juro para o banqueiro e o lucro para o empresário.

Numa perspetiva estruturo-funcional (Parsons, 1967; Davis e Moore, 1976), o trabalho seria uma base para ordenar estatutos e papéis ou serviria como indicador de classificações profissionais. Articulada com esta perspetiva conjuga-se a visão (neo)liberal de trabalho, a qual se traduz num "conjunto das ações que o homem em ordem a um fim prático, com a ajuda do cérebro, das suas mãos, de utensílios ou de máquinas, exerce sobre a matéria, ações que, por seu lado, atuando sobre o homem, o modificam" (Friedman e Naville, 1961). O trabalhador comporta-se de modo racional no mercado de trabalho na procura das oportunidades de trabalho oferecidas.

Porém, o trabalho não possui apenas dimensões estruturais e comporta outros aspetos (base de sustento, recompensa, motivo de satisfação, utilidade social) e é socialmente construído através de ações e significados subjetivamente atribuídos pelos atores sociais (cf. Weber, 1978; Simmel, 1977), quer dizer, não se limita à produção material de bens mas inclui todos os processos de produção de valores de uso e de troca, incluindo serviços. É tendo em conta uma perspetiva multidimensional que Poulantzas (1975) e Wright (1985) e, de modo mais consistente, Benschop (1993), Bourdieu (1996) e Burawoy (1979), problematizando a relação do económico com o político, o cultural e o religioso, introduziram abordagens multidimensionais e de síntese.

Sem entrar agora no velho debate sobre reprodução (cf. Bourdieu e Passeron, 1975; Bertaux, 1977) versus mobilidade social (cf. Berting, 1965; Dahrendorf, 1990; Goldhtorpe, 1987), importa salientar que, por regra, determinada estrutura social permite a reprodução e/ou o reforço social da maior parte dos membros de cada grupo social no seu seio mas admite que, em determinadas conjunturas e circunstâncias proporcionadas pela mobilidade espacial e respetivas oportunidades de vida, a potenciação e o investimento de determinadas capacidades, habilidades e demais recursos possam ora influenciar ora infletir as trajetórias biográficas ao ponto de tornar-se possível uma subida social. Do mesmo modo, a ocorrência de determinados ambientes adversos, a falta de oportunidades e a ocorrência de certos contratempos (doença, epidemia, desemprego, perseguição política) podem ocasionar e provocar uma descida social. Se, não obstante os constrangimentos estruturais e a lógica dominante da reprodução social, seria possível dar conta de processos e trajetórias de ascensão social, neste texto vamos incidir a reflexão sobre dois estudos de caso que traduzem processos de reprodução e descida social pela via da precariedade e do desemprego, como fenómenos crescentemente estruturais na economia e na sociedade capitalista nomeadamente nesta nova era do capitalismo cada vez mais automatizado que descarta força de trabalho. 
Mas o que é o desemprego, como se compreende e explica? Trata-se de um velho e recorrente fenómeno ou apresenta-se como uma situação própria do sistema capitalista?

De facto é só a partir dos finais do século XIX e com a introdução de máquinas e subsequente fase de mecanização e intensificação da industrialização que emerge o fenómeno do desemprego, pois até então os que não tinham ocupação eram designados de pobres ou mendigos. Para os liberais o desemprego é um fenómeno que deriva do desajustamento entre a oferta por parte das empresas e a procura de trabalho por parte das pessoas, desajustamento este resultante da rigidez dos salários, pelo que os trabalhadores desempregados deverão mover-se para onde haja trabalho de modo a voltar ao equilíbrio da oferta e procura. Ou seja, como o salário do trabalhador é considerado superior à receita suplementar produzida, o empresário tende a substituir o trabalhador por outro mais barato ou por substituir o trabalhador por máquinas ou equipamentos (v.g., dactilógrafas por computadores portáteis, portagens automáticas).

É, porém, nos anos 30 do século XX que se assiste ao desemprego maciço - o qual, segundo Keynes (2010), resulta de uma insuficiência na procura agregada de bens e serviços. Ou seja, havendo uma baixa no consumo, tal faz com que a produção diminua e o empresário necessite de menos trabalhadores. É este círculo vicioso que induz Keynes (2010) a sustentar que o desemprego tem uma dimensão involuntária e a afastar-se do fundamentalismo liberal avesso à intervenção estatal nesta como noutras matérias e se empenha num programa de criação de emprego pela implementação de infraestruturas pela via estatal, para o que se impunha um programa de investimento público, além do privado. A criação de emprego e o eventual aumento de salários estimulam o poder de compra, o aumento de consumo e, com este, o aumento da produção e a nova oferta de trabalho.

Para Marx (1974), o desemprego é resultante da lógica e funcionamento do próprio modo de produção capitalista que tende a manter uma massa maior ou menor de desempregados que o autor denomina "exército industrial de reserva” - para pressionar para baixo o nível de salários.

Sendo hoje o problema do desemprego objeto de crescente debate e preocupação social e política, sob o termo de desempregados cabem todos os indivíduos que, estando disponíveis para o trabalho, não trabalham e procuram ativamente emprego, compreendendo esta realidade uma dimensão objetiva (privação de emprego), uma dimensão institucional (classificação estatística) e uma dimensão subjetiva (vivência) (Rodrigues, 1988; OCDE, 1994: 26; Marques, 2000). São vários os tipos de desemprego: (i) sazonal - decorrente de variações na procura e oferta em certos períodos do ano; (ii) friccional - derivado de desencontro temporário entre a oferta e procura gerado por mudanças de emprego; (iii) tecnológico - resultante da introdução de novas tecnologias 
que eliminam postos de trabalho, sobretudo os mais desqualificados; (iv) conjuntural - dependente da insuficiência de procura de bens na economia e oferta em excesso de força de trabalho; $(v)$ estrutural - resultante de desajustamento continuado entre a oferta e a procura de trabalho, seja por aumento da população ativa nomeadamente com a entrada maciça de mulheres no mercado de trabalho sobretudo desde os anos 70 e 80 do século $\mathrm{XX}^{4}$, seja sobretudo porque a mecanização e a automatização dos processos produtivos por introdução de novas tecnologias vêm dispensar mão de obra, provocando desemprego de longa duração.

Nas fases mais avançadas do capitalismo predomina de longe o desemprego estrutural. Para entender a atual situação de desemprego, precariedade e incerteza que afeta uma parcela cada vez maior da população, importa enquadrar o fenómeno no processo mais geral de precarização estrutural na atual fase do capitalismo de dominante toyotista, que se foi desenhando e intensificando desde os anos 80 e 90 do século passado. Com efeito, tal como referem Antunes e Braga (2009), o capitalismo tem conhecido diversas metamorfoses no sentido de uma crescente informalização e precarização do trabalho, não só destruindo postos de trabalho pela automatização, como tornando mais descartável o trabalho e pressionando, a coberto de nova legislação laboral de cariz liberal, pela redução ou até desvalorização da força de trabalho, tal como assinalara Marx: “O modo de produção capitalista esbanja seres humanos, desperdiça carne e sangue, dilapida nervos e cérebro" (Marx 1974: 99). Com efeito, esta tendência, embora cada vez mais evidente na nova era do capitalismo, já fora detetada por Marx (1974) quando sustentava que o modo de produção capitalista, sem deixar de prosseguir a concentração de capital pela extração da mais-valia sob forma absoluta, tendia a intensificar o processo de acumulação através da extração da mais-valia relativa pela incorporação de tecnologias e força de trabalho mais qualificada, se bem que, na última década, também esta tenha vindo a ser fortemente atingida.

Neste quadro, para além do desemprego de longa duração afetando a inserção de faixas etárias jovens, uma das franjas mais atingidas por este processo são os trabalhadores mais idosos, sobretudo quando trabalhadores não qualificados, que o sistema e as empresas tendem a encarar como desnecessários, supérfluos. Embora este fenómeno tenha antecedentes desde os anos 30 do século passado, tem sido nas duas últimas décadas que o fenómeno tem

4 Segundo Manuela Silva (1983: 21 ss), esta entrada maciça de mulheres no mercado de trabalho nos anos 70 e 80 deveu-se, para além do processo de modernização do país, à rarefação de mão de obra masculina pela emigração masculina e sobretudo à necessidade de um segundo salário, dados os baixos salários dos homens-maridos. Acrescem ainda fenómenos como o aumento de divórcios, a recomposição de famílias e a mudança de mentalidades e de representações sobre o papel da mulher não só como esposa e mãe mas também como profissional fora de casa, assim como o reconhecimento efetivo da igualdade de direitos da mulher na sociedade, embora haja ainda caminho a percorrer neste aspeto. 
adquirido uma maior amplitude, levando autores como Demazière (1992) a falar não da crise de emprego mas da crise de desemprego. É sobre trabalhadores com 55 ou mais anos que este processo tem vindo a ter lugar, pelo que vamos trazer para primeiro plano as perceções, memórias e representações de duas pessoas com 55 e 61 anos atingidas pelo desemprego ou precocemente empurradas para a reforma.

\section{4. "0 trabalho faz viver a gente. Parar é morrer" - a história e memórias de Rui}

Seguidamente, daremos conta da situação de Rui que não se sente nada bem com a mesma, sente-se sem propósito, chocado com o fim de uma rotina que lhe dava um propósito diário e sentido de pertença e utilidade, cuja interrupção lhe cria um sentimento de mal-estar. Reaviva-se e até se sobrepõe, em termos de memória, a grata recordação de um coletivo de trabalho a que ele pertencia no passado.

Rui, de 55 anos, não podia crer que a empresa onde trabalhava desde os 15 anos terminasse daquela forma. Foi um grande choque perceber que uma empresa que tanto tinha produzido e tanto lucro tinha dado estava agora a fechar as portas por falência. Ainda se encontra com os seus colegas de trabalho, de cada vez que há plenários, já que o caso está agora em tribunal. Não deixou grandes amizades, apenas muitas saudades da "alegria que sentia no trabalho (...) e por receber um salário”. Em contraponto às memórias do trabalho no passado, diz que se sente muito mal com o desemprego, não consegue dormir, anda sempre muito nervoso e que a sua condição de saúde se agrava com a ansiedade que sente. "O meu próprio sistema nervoso, ele não aparenta, mas está aqui todo revoltado e isto piora a minha condição. Tenho ido ao médico regularmente. Ando de novo a não dormir à noite.” Não fora o amparo dos filhos, da mulher e da religião, estava ainda pior.

Revive os momentos passados no emprego, fala sobre a forma como desenvolveu um conhecimento intuitivo sobre a temperatura ideal dos fornos e a sua vantagem sobre colegas e chefias em função desse conhecimento, sobre a dureza das condições físicas de trabalho, das inúmeras horas extraordinárias que fazia e sobre o reconhecimento que sentia pela sua dedicação, não só monetária, mas também estatutária. Dentro da fábrica, recorda revendo-se como um trabalhador sério, comprometido, com uma noção forte de dever e de solidariedade. "Eu lutava, das 8 às 17. Eu era exigente na mesma com o pessoal, era para começar, começava-se, era para terminar, terminava-se”.

Fazendo uma retrospetiva das dificuldades e das exigências do emprego, que Rui aponta como responsáveis pela sua menor participação na vida familiar, ele reassume ter encarado o trabalho como um desafio ao qual gostava de corresponder. Mais, estava tão plenamente envolvido com o trabalho, que até 
se dispunha a trabalhar horas extra e a pensar em soluções para a otimização da produção mesmo depois do expediente: "A minha mulher dizia que eu vivia mais a fábrica do que a casa e era uma verdade."

Esta "ética" de trabalho diz tê-la interiorizado em contacto com a sua família de origem: "Do trabalho é que eu vivia. Não era só por causa do salário. É já de nós próprios, de família, somos todos assim, os meus irmãos, a minha irmã. Vivemos o trabalho e gostamos daquilo que fazemos e então pronto, empenhamo-nos no trabalho." Admite que, mesmo ganhando a lotaria, continuaria a trabalhar.

Durante os anos em que foi o "encarregado" da secção de fundição, ou seja, o segundo na disposição hierárquica, estava de tal forma embrenhado com o trabalho que não manteve qualquer outra ocupação ou interesse. O tempo livre usava-o para descansar a ver televisão, a dormir ou em passeios com a família.

Relata que, nos últimos anos, contudo, aproximou-se de um grupo espírita, no qual acabou por se assumir como médium. A possibilidade de ajudar os outros através do medianismo é entendida como um propósito para a sua vida, sobretudo agora que está desempregado. Mas esta atividade ocupa-o apenas um ou dois dias por mês, pelo que a sua importância é relativa. A maior parte das vezes, simplesmente não sabe o que fazer. Para já tem estado entretido com a supervisão das obras na casa do seu filho, mas há de ter que arranjar outra coisa, já que elas estão quase terminadas.

Não pensa em voltar a trabalhar. Não que não o desejasse, mas está seguro de que ninguém o contratará com a idade que tem. Sente-se injustiçado e posto de parte, pois, olhando para o seu passado e competências, diz que ainda poderia contribuir de forma positiva, mesmo que fosse apenas através da transmissão dos seus conhecimentos, ensinando aprendizes, mas nem para isso parecem existir oportunidades.

O mercado de trabalho, aliás, está demasiado saturado e quase não oferece oportunidades de integração. Não basta procurar emprego recorrendo aos mecanismos habituais, porque não existem posições que ele possa ocupar de acordo com os seus conhecimentos. Até porque os únicos empregos aos quais poderia aceder são pior pagos do que o subsídio de desemprego e muito instáveis.

Afinal, agora, a possibilidade de autodeterminação é muito diminuta: não só não conseguirá trabalhar de novo, como também não conseguirá manter o nível de vida a que estava habituado no passado. O que mais o preocupa é precisamente a diminuição do rendimento, e a noção de que agora é dependente de um subsídio estatal, que não tem um papel produtivo, o que percebe de forma negativa. 
Não estou entalado (...) mas comprei o meu carro novo (...) e o apartamento que ainda o estou a pagar (...) e o meu salário está a metade. (...) O meu filho casou o ano passado (...), o outro vai casar e está no desemprego e isto mói... (...) nós vivíamos encantados da vida, tínhamos o nosso trabalhinho, não é, vivíamos livres de vergonhas, o dinheiro chegava, trabalhava-se, mas o dinheiro chegava. (...). Hoje tenho que o ir buscar onde o pus (referindo-se às poupanças), mas ele acaba. Tenho uma despesa geral talvez para aí 1000 euros e eu não ganho mil euros e vou buscar o que amealhei, o que quer dizer que amanhã acaba. E se eu dissesse isto vai, isto vai virar, vou trabalhar, vou receber, faço mais umas horas e vou normalizar tudo, mas não ...para mim, com 55 anos acabou (... ) assim vou para o desemprego, não produzo, vou buscar ao Estado, mas não estou a produzir nada. (Rui)

Ainda faltariam 10 anos, em circunstâncias normais, para a reforma, mas neste momento, não tem qualquer outra possibilidade. Relembra que, no passado esteve desempregado durante três meses (o espaço de tempo decorrido entre a falência da empresa onde trabalhou entre os 15 e os 21 e a integração nessa mesma empresa, comprada entretanto por outro grupo) mas, apesar dos problemas económicos que lembra da altura, com três filhos pequenos, não percebia grandes dificuldades em voltar a trabalhar. Não só porque a crise não era tão grave, mas sobretudo porque era novo. Agora não só não tem as habilitações necessárias para encontrar emprego, como está numa faixa etária que é indesejada no mercado de trabalho. Discorda de quem apregoa que, para encontrar emprego, basta procurar.

O desemprego nesta fase da sua vida consagrou-lhe antecipadamente o rótulo de "velho", é assim que agora é visto pelos empregadores. Mas não está de acordo com esse rótulo, porque se sente com capacidades e disposto a aprender uma nova função, mesmo com as limitações que encontra em virtude da sua doença.

O envelhecimento será mais visível agora que perdeu o emprego e não tem maneira de se exercitar intelectualmente. O declínio é inevitável, mas poderia ser menos evidente se ainda se mantivesse ativo durante mais alguns anos. O desemprego pode ainda contribuir para a deterioração da sua saúde e da sua "vitalidade", tal como recorda ter acontecido a um antigo chefe seu, que, com 63 anos, depois de alguns meses no desemprego, viu diminuídas as suas capacidades físicas e intelectuais E, relativamente à sua vivência do passado, sustenta que o trabalho permite a necessária atividade física e mental que evita o declínio. Mais, garante ainda que o desenvolvimento de conhecimentos práticos específicos, bem como a sua aplicação continuada, evitava que desaparecessem: “(...) parar é morrer. Uma pessoa no ativo, pratica (...) eu olhava para o forno e sabia a que temperatura estava o material (...), só se sabe depois de muitas práticas, muitos dias”.

Quanto ao futuro, este não lhe reserva nenhum projeto, nenhuma ambição, senão pagar as dívidas e ultrapassar a insegurança financeira. Espera que, 
em dez anos, a casa de família seja inteiramente propriedade do casal, representando não só a concretização de uma vida de trabalho, como o garante de estabilidade durante a velhice.

\section{5. "Deixa trabalhar os novos" - A história e as memórias de Vítor}

Vítor diz-se aliviado da sobrecarga física e psicológica e dos constrangimentos de um horário que o impediam de estar com a família. Mas a sua idade de 61 anos encontra a reforma e o subsequente fim do trabalho assalariado como um tempo apropriado.

Vítor relembra as suas origens, dizendo ter nascido no seio de uma família numerosa, filho de trabalhadores à jorna que passavam muitas dificuldades para conseguir alimentar os filhos. Seguidamente relata como começou a trabalhar aos 14 anos, altura em que conclui a instrução primária, como ajudante numa fábrica de tijolos. A falência dessa empresa viria a lançá-lo no desemprego por dois anos, mas retoma a atividade como aprendiz numa conceituada metalúrgica de Braga, onde aprendeu o seu ofício aos 16 anos. Aos 21, prestes a casar, entra para uma empresa no mesmo ramo que lhe oferecia melhores condições de trabalho e salariais, por intermédio da noiva, que já lá trabalhava. Manteve-se por 40 anos como operário na linha de montagem.

Entretanto, as dificuldades financeiras que a empresa enfrentava nos últimos anos levaram à dispensa de alguns trabalhadores. Vítor, na altura com 61 anos, percebe-se seriamente cansado do trabalho árduo, desgastado pelo trabalho realizado em espaço fechado, e claramente desmoralizado com a estagnação da produção que o obrigava, tal como os outros, a "esconder-se pelos cantos [da fábrica] porque não tinha trabalho". Por todos esses motivos, confessa ter-se voluntariado para ser um dos trabalhadores que a empresa iria demitir para diminuir os custos de produção. Por essa altura a mulher, que trabalhava na mesma empresa, já tinha sido demitida. E, pela sua parte, desabafa: “Também eu me quis vir embora, porque já estava encostado à banca. (...)”, sem nada que fazer o dia todo.

Na reconstrução do seu passado recente Vítor diz ter consciência e ser particularmente sensível à situação de precariedade que os restantes trabalhadores que ficaram enfrentam. Ao relembrar a sua trajetória, sente-se muito comovido, diz que deixou muitos amigos na fábrica e, após uma pausa, passa a explicar que, com os baixos salários que os operários auferem, sem margem para poupança, com avultadas despesas e filhos menores, dificilmente conseguirão gerir uma eventual situação de desemprego. Acrescenta que esta situação é injusta, dadas as condições de trabalho e remuneração, demonstrando uma clara consciência de exploração a que ele e os demais trabalhadores foram sujeitos.

É com base na experiência laboral do passado que de modo assertivo assegura que o trabalho assalariado está totalmente posto de parte para ele, o corte 
é total, agora que está prestes a reformar-se. Não tem qualquer ensejo em voltar ao mercado de trabalho não só pela memória que lhe fica do trabalho enquanto experiência de privação da sua liberdade, mas também porque, entende o trabalho como um bem escasso, que deve estar acessível aos que dele têm maior necessidade para sobreviver, sobretudo quando têm filhos a cargo, como explica:

Eu, deixando de trabalhar nunca mais trabalho na vida. Faço as coisas em, casa, mas por conta de outrem nunca mais. Porque estou a roubar um posto de trabalho. A malta nova que trabalhe, que bem precisa.

Contudo, como coloca em vários momentos, esteve muito envolvido no passado com as funções que exercia pelo propósito diário que o emprego lhe conferia, o uso estruturado de tempo ou a rotina, tão importantes para o seu bem-estar. Evidencia inclusivamente que a necessidade do trabalho ultrapassava o seu propósito financeiro: "Saísse o dinheiro que saísse (numa lotaria), trabalhava na mesma até à idade da reforma porque aquilo era um ritmo que eu tinha e eu gostava”.

Agora diz que se sente muito bem com o desemprego, inclusivamente rejuvenescido. Reforça mesmo a ideia de que, com o passar dos anos, este tipo de trabalho se torna cada vez menos desejável, mais penoso, atendendo ao desgaste que provoca e à possibilidade de ter outro tipo de experiências. O fim do trabalho permitiu-lhe libertar-se das condições físicas severas a que estava sujeito e das restrições no uso do tempo.

A reforma era muito bem dada antes dos 60 anos, pelo menos para quem estiver em cativeiro [referindo-se ao local de trabalho, um pavilhão que permite uma relação com o espaço exterior muito limitado]. Quem está ao ar livre, pode ser aos 60 anos, mas para quem está em cativeiro, como nós estivemos, aos 55, 57 é bem dada.

Sobressai ainda da entrevista que o relativo bem-estar associado ao desemprego passa pelo entendimento de si como uma pessoa envelhecida e agastada pelo trabalho. "Já tinha 48 anos de trabalho... estava a ver a mandarem gente nova embora e a mim e à minha mulher queriam matar-nos lá a trabalhar. (...) Deixa trabalhar os novos, claro que queria sair."

O desemprego, amiúde, mas injustamente atribuído pelos outros à incompetência, irresponsabilidade ou inutilidade do indivíduo, pressupõe a desqualificação e a desvalorização social do desempregado, o que causa grande sofrimento psicológico. Segundo Vítor, é expectável que um desempregado procure emprego, sobretudo se dele depender uma família. Contudo, num momento em que não se percebem oportunidades no mercado de trabalho, as tentativas de reintegração saem normalmente goradas. O desemprego estrutural é algo inelutável, que ultrapassa o indivíduo, pelo que não se espera grande resistência, 
mas capacidade de acomodação à situação. Mais, lutar pela reintegração no mercado de trabalho é algo que se exige aos desempregados mais novos, não aos "velhos". Vítor assume e interioriza uma autoimagem de uma pessoa que, de forma legítima, sem culpas, se pode afastar do mercado de trabalho, sem sofrer de um estigma de "desempregado".

Ele é um "reformado", apesar de ter 61 anos e não ter atingido a idade instituída para a reforma. Não procura emprego, não só tendo em conta a falta de procura de mão-de-obra, mas também porque age de acordo com as expectativas que lhes são traçadas por outros. Diz resignar-se a uma realidade que não pode alterar, mas que é "normal”, “natural” ou expectável: o envelhecimento. Este processo biológico representa a saída do mercado de trabalho não só em virtude da deterioração das capacidades físicas e mentais, como também porque considera cumprido o seu papel na sociedade. Acrescenta que não se deve esperar que um "velho desempregado" procure emprego, até porque vai "roubar um posto de trabalho aos mais novos".

Agora que o trabalho de fábrica acabou, parece só lhe restar usar o tempo que tem antes de morrer da forma mais satisfatória possível: "no campismo, tenho lá muitos amigos de todos os lados. A gente junta-se todos, aos fins de semana há um ranchozito, faz-se uma churrascada, juntam-se uns amigos até um dia, até ir para ali [apontando para o cemitério, portas meias com a sua casa]. Desta feita, não lhe restam muitos planos por cumprir. Entende que deve cuidar da sua saúde e assumir o cuidado dos netos:

depois continuo nisto à espera de ir num sobretudo para ali [aponta para o cemitério]. O meu futuro é esse (...). Leio uns livros, uns jornais e vou andando, de resto não trabalho mais, nem eu nem a minha mulher. Agora vem o neto e já sei que vamos olhar por ele. (...) Olho por ele e é uma maravilha.

Os dias (re)compõem-se nestes novos espaços; quanto ao novo propósito da vida, este passa por esperar a morte.

\section{Conclusão}

Pelos relatos e testemunhos de síntese destes dois trabalhadores desempregados mas já com longos percursos de vida e de trabalho, nomeadamente por se terem iniciado muito precocemente no mundo do trabalho, estamos perante dois homens que se sentem profundamente explorados e injustiçados não só pela sua longa trajetória de trabalho, como sobretudo pela sensação de serem descartáveis e 'inúteis' no fim das suas vidas: o Rui, impregnado duma memória e de um sentimento de pertença e vivência coletiva na empresa no passado, acusando a desvalorização da sua pessoa no presente pelo sistema, a sua inconformidade, enquanto desempregado em pré-reforma quando poderia ser útil 
pela suas competências específicas; um outro, mais consciente da sua condição de trabalhador assalariado que, no quadro do sistema capitalista, vê o capital e o patronato como sua classe antagónica, evidenciando na reconstituição da sua trajetória um espírito contestatário pelas condições de vida e exploração de 48 anos de trabalho e, como tal, vê-se aliviado com o desemprego e a reforma antecipada aos 61, num corte radical com a exploração de que diz ter sido alvo.

Estes são, todavia, dois exemplos que traduzem duas memórias e dois olhares com elementos comuns e diferenciados na sua antiga condição de trabalhadores assalariados e, de novo, na sua nova condição de desempregados, evidenciando alguns aspetos contrastantes mas reais: para Rui, o trabalho recordado como base de pertença e realização profissional mas em que o desemprego, quando sobrevindo, gera tristeza, sofrimento, inconformidade ou mesmo revolta por o despersonalizarem e tornarem dispensável; para Vítor, o trabalho, enquanto processo vivido de exploração, objetificação, mercadorização e alienação, proporciona-lhe sociabilidades e amizades com os demais colegas, mas consciência crítica perante condições de trabalho e o próprio sistema. Quando a reforma antecipada surge, Vítor sente que esta não representa um corte com o sistema de exploração mas uma libertação sua da penosidade do trabalho, além de proporcionar-lhe novas possibilidades de ocupação e sobretudo atividades de lazer que considera como produtoras de sentido e satisfação pessoais. Em qualquer um dos casos, não obstante a diferenciada forte perceção da exploração de que foram vítimas ao longo das suas vidas, assim como a diferente vivência do desemprego e subsequente reforma, o trabalho é revivido nas suas memórias e vivências do passado como base de identidade social e mesmo de utilidade social.

\section{Referências}

ALMEIDA, João Ferreira (1986), Classes sociais nos campos. Camponeses parciais numa região do Noroeste. Lisboa: Instituto de Ciências Sociais, Universidade de Lisboa.

ALMEIDA, João Ferreira de; COSTA, António Firmino; MACHADO, Fernando Luís (1994), "Recomposição socioprofissional e novos protagonismos", in A. Reis (coord.) Portugal - 20 anos de Democracia. Lisboa: Círculo de Leitores.

ANTUNES, Ricardo; BRAGA, Ruy (2009), Infoproletários. A degradação real do trabalho virtual. São Paulo: Boitempo.

AUGE, Marc (1998), Les formes de l'oubli. Paris: Payot \& Rivages.

BENSCHOP, Albert (1993), Klassen. Ontwerp van een transformationele klassenanalyse. Groningen: Wolters-Noordhoff.

BERTAUX, Daniel (1977), Destinos sociais e estrutura de classe. Lisboa: Moraes Editora.

BERTING, J. (1965), "Statusincongruentie en sociale mobiliteit". Sociologische Gids, 12 (1): 2-18. BOURDIEU, Pierre (1996), "Les nouvelles formes de domination dans le travail" in Actes de la Recherche en Sciences Sociales, I e II: 114-115.

BOURDIEU, Pierre; PASSERON, Jean Claude [1975 (1970)], A reprodução: elementos para uma teoria do sistema de ensino. Rio de Janeiro: Francisco Alves. 
BURAWOY, Michel (1979), Manufacturing Consent. Chicago e Londres: University of Chicago Press.

CANDAU, Joel [2012 (1996)], Memória e Identidade. São Paulo: Contexto.

CONNERTON, Paul (1989), How Societies Remember. Cambridge: Cambridge University Press.

COSTA, António Firmino da (1987), "Novos contributos para velhas questões da teoria das classes sociais”. Análise Social, XXIII (98): 635-686.

COSTA, António Firmino; MAURITI, Rosário; MARTINS, Susana (2004), "Classes Sociais na perspectiva comparada: estruturas europeias e activas e instrumentos de análise", in $V$ Congresso Português de Sociologia. Braga: Universidade do Minho.

DAHRENDORF, Ralf (1990), "A New Social Contract”, in R. Dahrendorf (org.), The Modern Social Conflict - An Essay in the Politics of Liberty. Berkeley e Los Angeles: University of California Press.

DAVIS, Kingley; MOORE, Wilbert E. [1976 (1945)], “Alguns princípios de estratificação”, in O. Velho et al. (org.) Estrutura de classes e estratificação social. Rio de Janeiro: Zahar Editores, 115-132.

DEMAZIÈRE, Didier (1992), Le chômage en crise? La negotiation des identities de longue durée. Paris: Presses Universitaires de Lille.

DURKHEIM, Émile [1977 (1893)], A divisão do trabalho social. Lisboa: Presença.

DURKHEIM, Émile [1991 (1915)], Formes élémentaires de la vie religieuse. Lisboa: Presença.

ESTANQUE, Elísio (1999), Entre a fábrica e a comunidade. Porto: Afrontamento.

ESTANQUE, Elísio; MENDES, José Manuel (1997), Classes e desigualdades sociais em Portugal. Um estudo comparativo. Porto: Afrontamento.

FRIEDMAN, George; NAVILlE, Pierre (1961), Traité de Sociologie du Travail. Paris: Armand Collin.

GOLDTHORPE, John H. (1987), Social Mobility and Class Structure in Modern Britain. Oxford: Oxford University Press.

HALBWACHS, Maurice [1968(1949)], La mémoire collective. Paris: PUF.

HALBWACHS, Maurice [1994 (1924)], Les cadres sociaux de la mémoire. Paris: Albin Michel.

KEYNES, John M. [2010 (1936)], Teoria Geral do emprego, do juro e da moeda. Lisboa: Relógio d’Água.

LE GOFF, Jacques (1978), La nouvelle histoire. Paris: Retz, 57-96.

MARQUES, Ana Paula (2000), "Repensar o mercado de trabalho: emprego vs desemprego", Cadernos do Noroeste, Série Sociologia, Sociedade e Cultura, 13 (1): 133-155.

MARX, Karl [1974 (1867)], O Capital. Lisboa: Delfos.

MARX, Karl; ENGELS, Friedrich [1976 (1846)], A ideologia alemã. Lisboa: Presença.

MONTESPERELli, Paolo (2000), Sociología de la memoria. Buenos Aires: Ediciones Nueva Visión.

MORA, Teresa (2009), Viagem, Utopia e Insularidade: narrativas fundadoras da ciência e da sociedade moderna. Lisboa: Fundação Calouste Gulbenkian.

NORA, P. (1978), “Mémoire collective” in J. Le Goff (org.), La nouvelle histoire. Paris: Retz, 57-96.

OCDE (1994), L'Etude de l'OCDE sur l'Emploi: Faits, Analyse, Stratégie. Paris: OCDE.

PARSONS, Talcott (1967), "Una revisión analítica de la teoría de la estratificación social” in Ensayos de Teoría Sociológica. Buenos Aires: Paidós, 333-378.

PARSONS, Talcott [1988(1951)], El sistema social. Madrid: Alianza Editorial.

PEREIRA, Virgílio Borges (2006), Classes e culturas de classe das famílias portuguesas. Porto: Afrontamento.

PINTO, José Madureira (1985), Estruturas sociais e simbólicas nos campos. Porto: Afrontamento. POULANZAS, Nicos (1975), Classes in Contemporary Capitalism. London: NLB.

QUEIROZ, Maria Cidália (2007), "A teoria das classes sociais em Bourdieu: primado das relações de concorrência sobre as de subversão. Qual o efeito social desta teoria?”, in J. M. Pinto 
e V. B. Pereira (org.), Pierre Bourdieu. A Teoria da prática e a Construção da Sociologia em Portugal. Porto: Afrontamento, 59-90.

RIBEIRO, Fernando Bessa [2010 (2004)], Entre martelos e lâminas: dinâmicas globais, politicas de produção e fábricas de caju em Moçambique. Porto: Afrontamento.

RODRIGUES, Maria João (1988), O sistema de emprego em Portugal. Crise e mutações. Lisboa: Publicações Dom Quixote.

SCHUTZ, Alfred; LUCKMAN, Thomas (1977), Las estructuras del mundo de la vida. Buenos Aires: Amarrortu Editores.

SILVA, Manuel Carlos (2012), “Trabalho, profissões e género” in M. C. Silva e A. P. Marques (org.), Trabalho, Técnicas e Mundo. Perspectivas e Debates. Vila Nova de Famalicão: Húmus, 135-155.

SILVA, Manuel Carlos (1998), Resistir e Adaptar-se. Constrangimentos e estratégias camponesas no Noroeste de Portugal. Porto: Afrontamento.

SILVA, Manuel Carlos (2009), Classes Sociais: condição objectiva, identidade e acção coletiva. Vila Nova de Famalicão: Húmus.

SILVA, Manuela (1983), A igualdade de oportunidades da formação profissional para as mulheres. Lisboa: Comissão da Condição Feminina.

SIMMEL, Georg (1977), Sociologia. Estudios sobre las formas de socialización. Madrid: Revista de Occidente/Alianza Editorial.

SOBRAL, José Manuel (1999), “Da casa à nação: passado, memória e identidade”. Etnográfica, III (1):71-86.

TODOROV, T. (2000), Los abusos de la memoria. Barcelona: Paidós.

WEBER, Max [1978 (1920)], Economy and Society, editado por G. Roth e C. Wittich. Berkeley \& London: University of California Press.

WEBER, Max [2001 (1922)], Il metodo delle scienze storico-sociali. Milan: Ediziono de Comunità.

WRIGHT, Eric Olin (1985), Classes. London \& New York: Verso.

Submetido: 02-02-2016

Aceite: 19-06-2016 